\title{
Histopathological changes of sub chronic toxicity induced by oral administration of Malathion in Rock dove pigeons (Columba livia)
}

\author{
Saleh K. Waleed M.S. \\ Coll. of Vet. Med. Unive/ of Basrah
}

\begin{abstract}
The objective of the present study was to investigate the histopathological changes of the sub chronic toxicity of Malathion as organphosphorus insecticide in Rock dove pigeons ( Columba livia) treated orally with $6 \mathrm{mg} / \mathrm{kg}$ and $4 \mathrm{mg} / \mathrm{kg}$ body weight. The histopathological changes of central and peripheral nervous systems, liver, kidney, skin of pigeon after three month of treatment were included, marked vacuolation of nerve fibers of spinal cord and sciatic nerve, periportal fibrosis and liver congestion, degenerate renal cortical tubules ,associated with loss of epithelial lining and disorganization of epithelial lining, and cortical areas of inflammatory cells with congestion of blood vessels, and dermal fibrosis and inflammatory cells of the skin
\end{abstract}

\section{Introduction}

Malathion is an organophosphours insecticide and has a wide range of use in agriculture, veterinary medicine and public health. However, the unregulated use and its aerial application over large agricultural and urban area has caused sever environmental pollution and potential health hazards (1) Malathion is extensively used in commercial poultry industries in middle east, including Iraq to control external parasites ( ticks, lice, mites etc...) of poultry birds (2).Exposure to insecticide, include malathion may cause a wide variety of clinical signs depending upon the nature and concentration of chemical, the duration of exposure, the species, age, nutritional and health status of animal (3). The signal most important mechanism of the toxic action of these insecticide in animals is inhibition of acetylcholine esterase at the never terminals, and this causes acetylcholine Mode of Action:

Malathion is toxic via skin contact, ingestion, and inhalation exposure. Malathion and other organophosphate insecticides bind to the enzyme acetylcholinesterase (AChE) at nerve endings throughout the bodies of insects and other organisms. Under normal circumstances, AChE binds to the neurotransmitter acetylcholine (ACh) at the nerve junction, effectively ending the stimulation of the next neuron(8). When accumulation that sub sequently causes a series of muscarinic, nicotinic and central nervous system effects (4). (5) have reported the Arial spraying of malathion reduced the hatchability of embrynoated chicken eggs. (6) reported that malathion dipping causes marked alteration in different enzymic profile and gross parameter related to carbohydrate protein and lipid metabolism in poultry birds. The acute oral $\mathrm{LD}_{50}$ values for various bird species are mallards $1485 \mathrm{mg} / \mathrm{kg}$; Pheasant $167 \mathrm{mg} / \mathrm{kg}$; black birds over $100 \mathrm{mg} / \mathrm{kg}$ and chicken $525 \mathrm{mg} / \mathrm{kg}$ ( 7).Because little information is available in this field, this study was conducted to investigate the sub chronic toxicity of malathion in pigeons, also oarganophospherous insecticide toxicity in pigeons which has been used as a model for such toxicity.

AChE is bound by malathion's metabolite malaoxon, ACh accumulates at the nerve junction and results in overstimulation of the nervous system Bioactivation of malathion is necessary for it to exert its toxic effect. Bioactivation is primarily mediated by cytochrome P450 enzymes in the liver, which create the active metabolite malaoxon through oxidative sulfuration. Malaoxon is considered to be 22 times more toxic than the parent 
malathion from acute dietary exposure and 33 times more toxic by all routes of exposure from short-term and mediumterm exposures. $(9,10)$.) Chickens are especially vulnerable to pesticide toxicity because poultry houses and birds are

\section{Aims of the study the study}

was to investigate the histopathological changes of sub chronic toxicity of malathion of pigeons.

\section{Materials and Methods}

A total of 30 rock dove pigeons (Columba livia) were purchased from the local market in Basrah province within body weight average $300-400 \mathrm{~g}$. The birds were divided into three groups. All groups were dosed orally with malathion. Group A treated with high dose of malathion , and group B treated with intermediate dose of malathion, while group $\mathrm{C}$ served as control group.Pigeons reared in separated cages of $100 \times 100 \times 80 \mathrm{~cm}^{3}$ at the poultry disease unit, college of veterinary medicine in Basrah university under suitable conditions, water and feed were supplied ad libitum. Group A were administrated orally with $6 \mathrm{mg}$ of malathion .Group B were administrated $4 \mathrm{mg}$ of malathion . the dosages were chosen according to maximum toxic dose which was found in a trail on a few pigeons before the start of

\section{Results}

Our study was revealed a histopathological changes of central and peripheral nervous systems, included marked vacuolation of nerve fibers of the spinal cord and sciatic nerves, as shown in figures (1,2,9 and 10), liver congestion ,degenerate renal cortical tubules dusted with pesticides. The sweepings and screenings from government depots that are sold as poultry feed, after being declared as unfit for human consumption, may be contaminated with pesticides. (11).

the study.Malathion (Cairo, Egypt) was obtained from the local market in Basrah province.The malathion was further diluted in distilled water to obtain the desired concentration for oral dosing by a gavage needle. The solution was prepared and used immediately. The doses of the malathion were used according to the active ingredients of substance .Ninety days later all remaining birds were killed by decapitation. Brain, spinal cord, sciatic nerve, liver, kidney, and heart samples were also collected for the histopatological examination. Tissue samples were kept in $10 \%$ neutral buffered formalin and the histopathological preparations was carried out according to(12),to obtained histological section 5 micrometer in thickness ,and then stained with Haematoxylin and Eosin.

,associated with loss of epithelial lining and disorganization of epithelial lining ,cortical areas of inflammatory cells with congestion of blood vessels, dermal fibrosis and inflammatory cells of the skin , as shown in figure $(3,4,5,6,7$ and 8). 


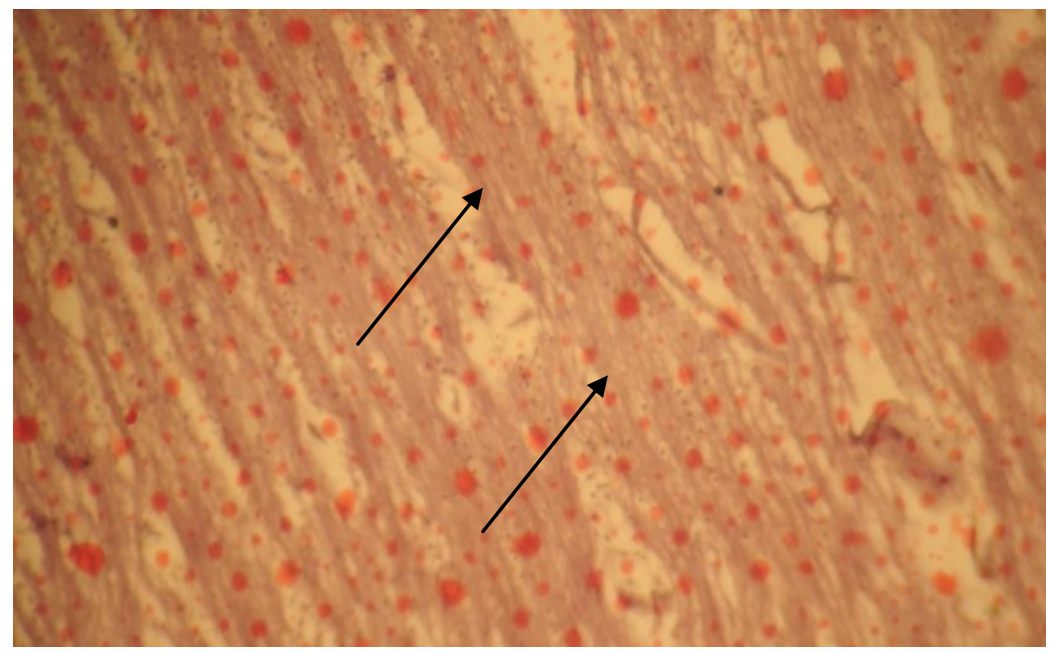

figure(1) group B. spinal cord. White mater. Longitudinal section. Vacuolation of nerve fibers. H\&E. $400 \mathrm{X}$.

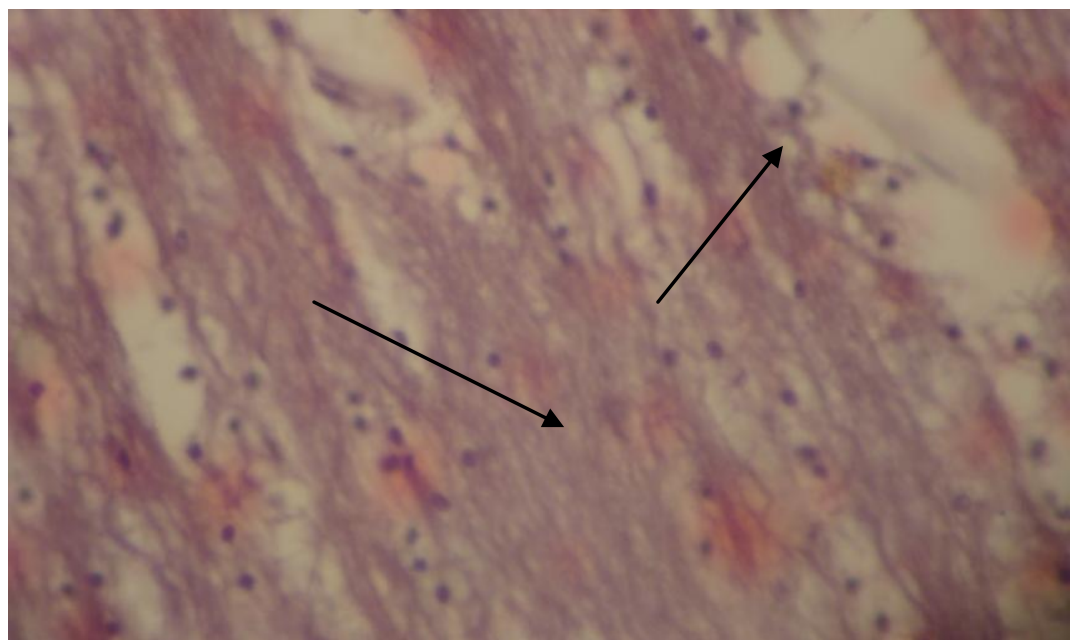

Figure. (2) group A. Spinal cord. White mater. Longitudinal section. marked Vacuolation of nerve fibers. H\&E. $400 \mathrm{X}$.

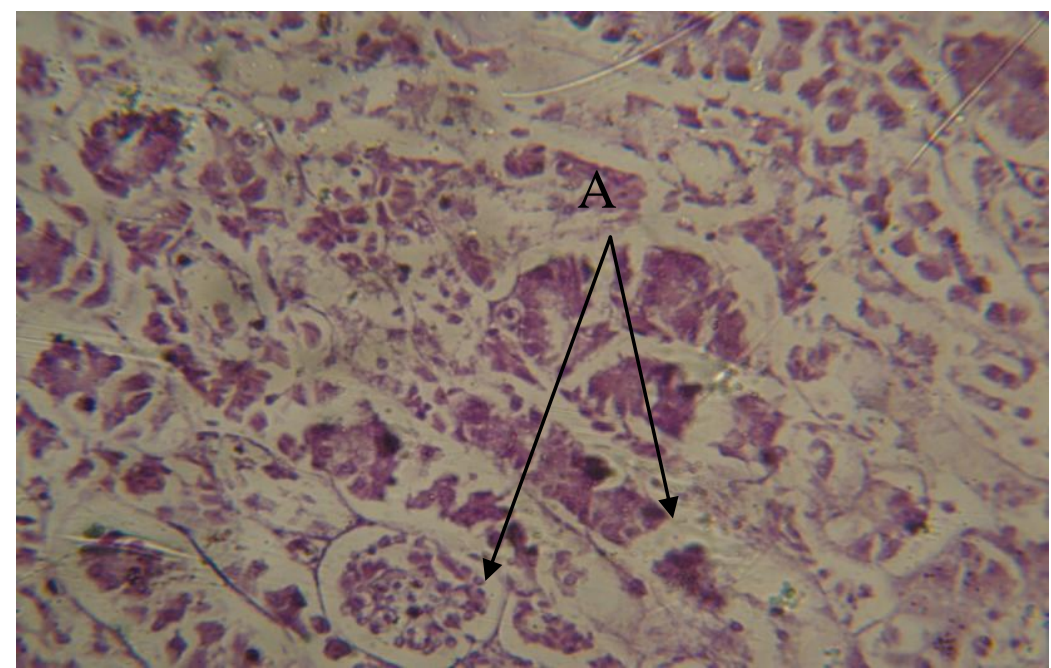

Figure3-a- group A- cortex .kidney. A. degeneration and necrosis of epithelial lining of kidney tubules .Glomerulonephritis H \&E 400 X. 


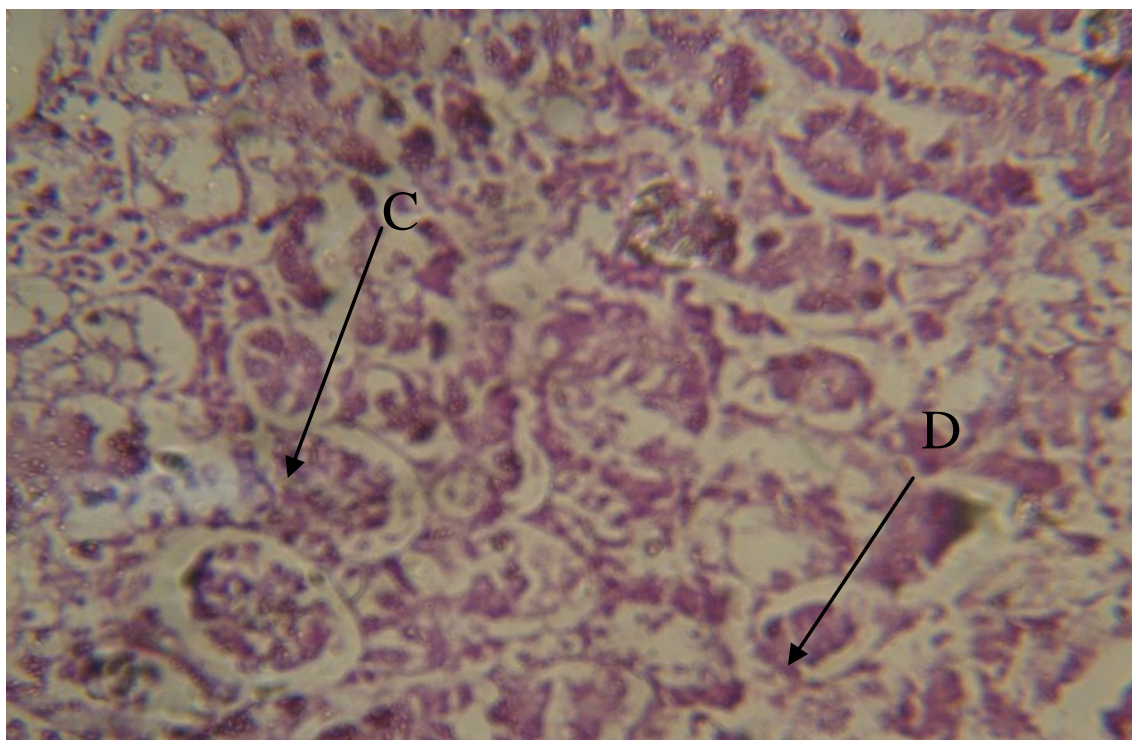

Figure3-b-group A. kidney. C. Inflammatory cells. D. degenerate cortical tubules H\&E 400 $\mathrm{X}$.

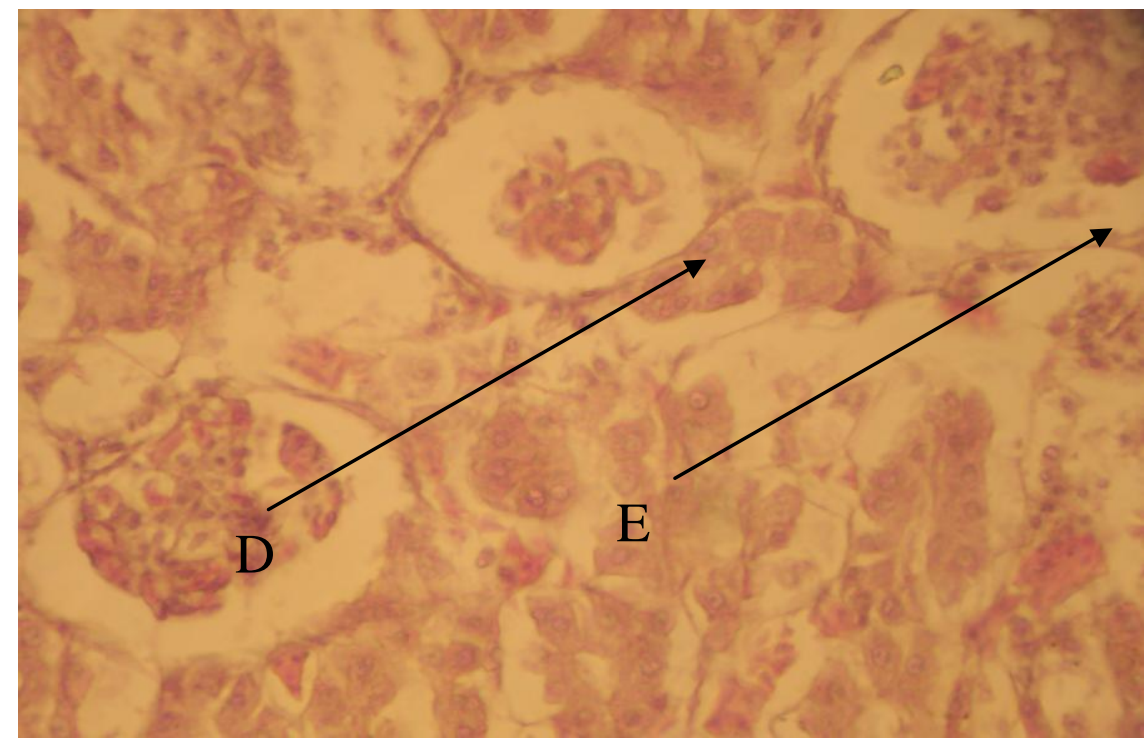

Figure 4.group B .kidney. atrophy of glomrulus, dilation of bowman capsule.H\&E 400 X

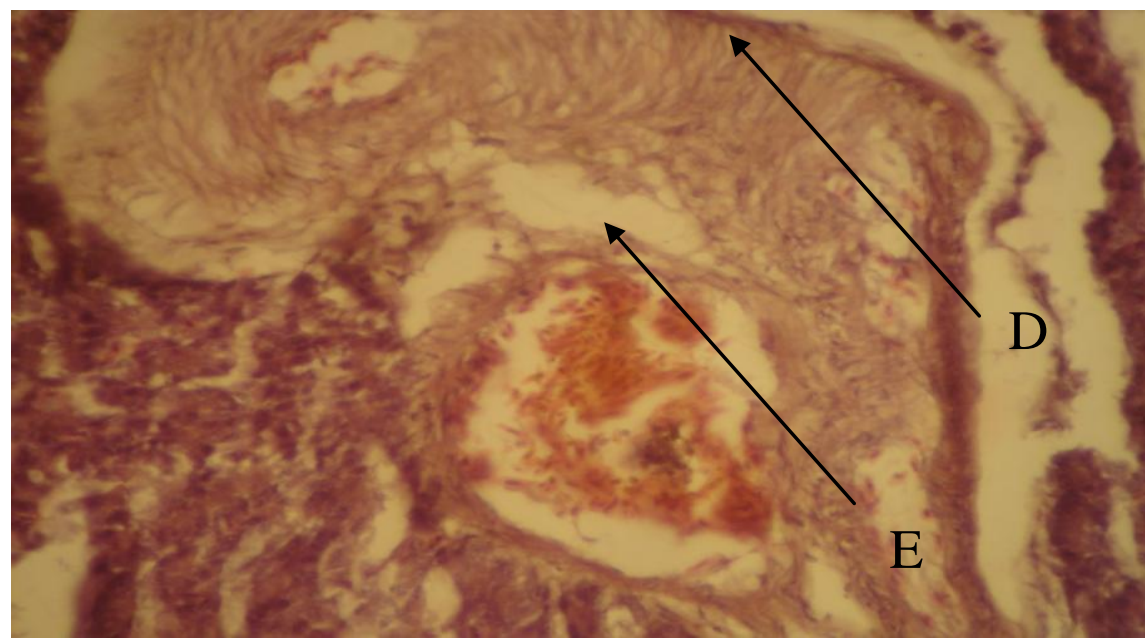

Fig5.a.group A.liver.periportal fibrosis, congestion of hepatic artery ,H\&E $400 \mathrm{X}$ 


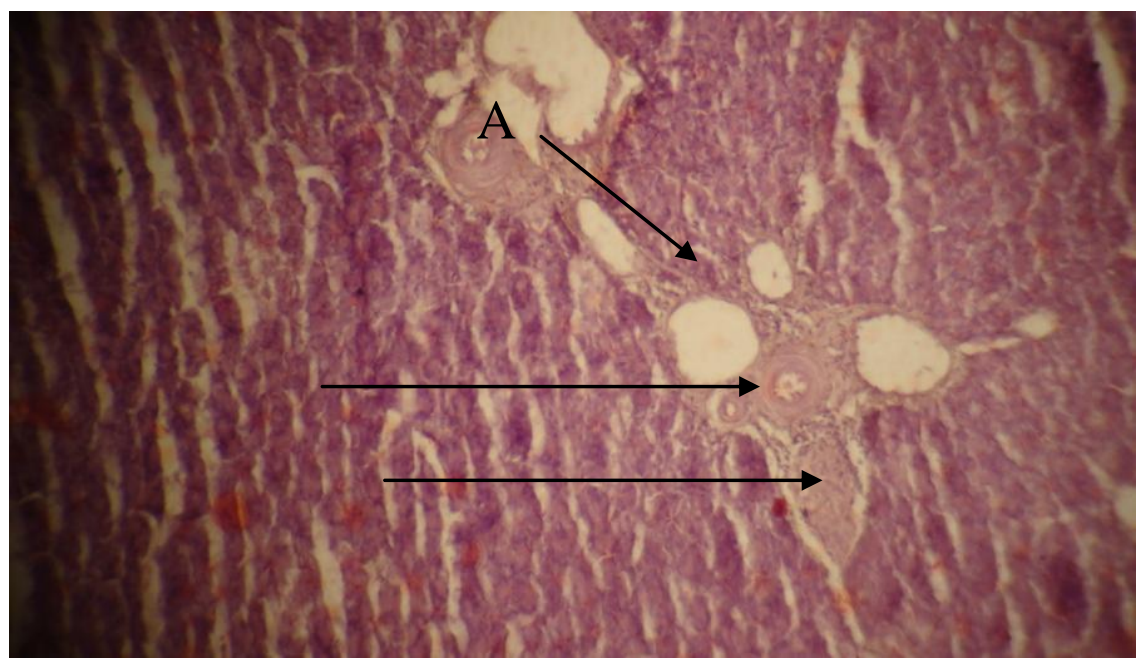

Fig 6.group B. liver. A.degenerate of hepatic cells. the pointed area are hepatic triad, consist of hepatic artery, hepatic vein ,bile duct and lymph vessel .

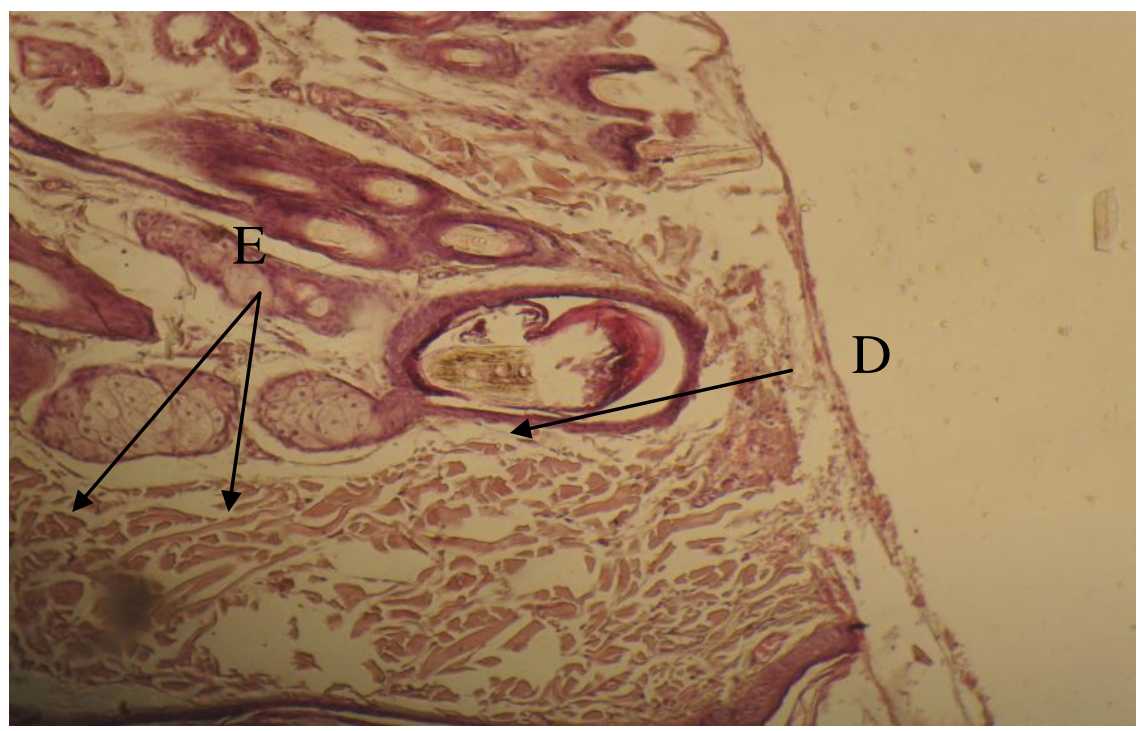

Fig 7. group A. skin. D. Hair follicle , E. sebaceous gland H\&E .400 X

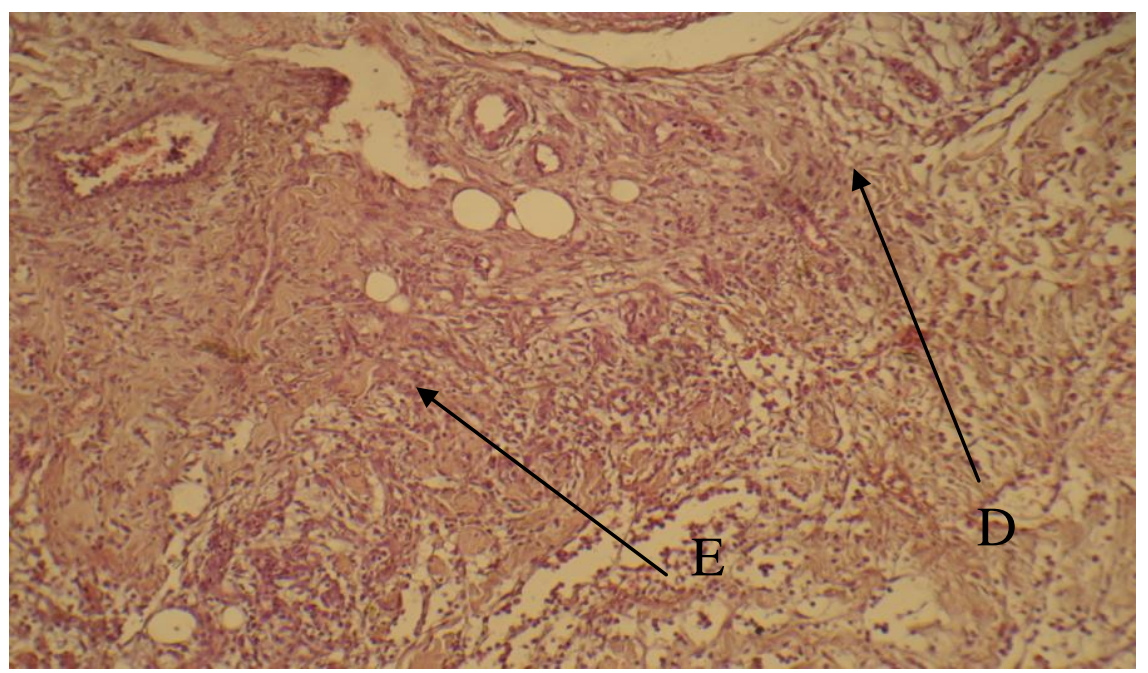

Fig 8.group A.skin of pigeon.. dermal fibrosis, dermal lymphocytes .H\&E $400 \mathrm{X}$. 


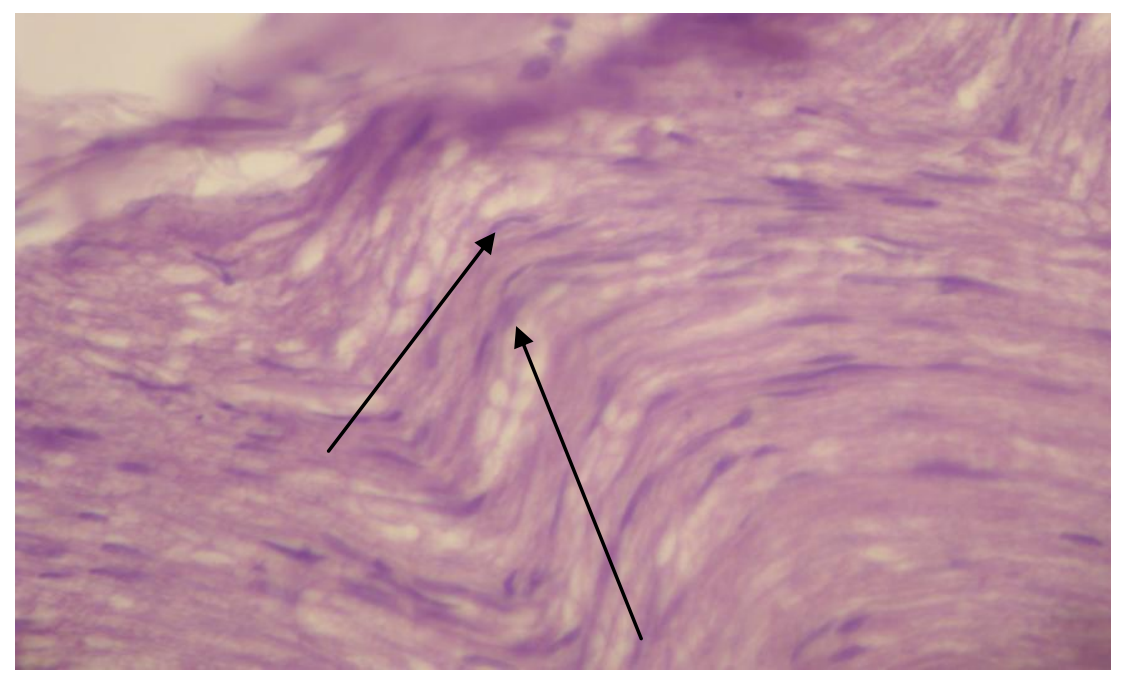

Fig 9 .group A. Sciatic nerve. marked vacuolation of nerve fibers.H\& E $400 \mathrm{X}$

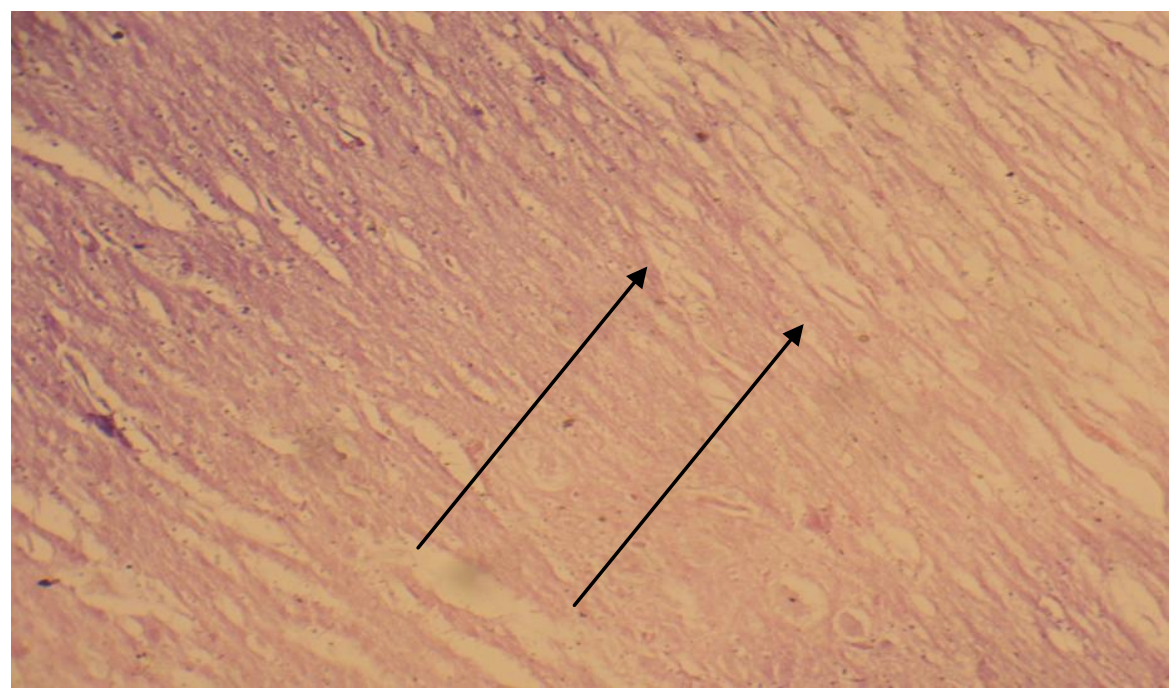

Fig 10.group B sciatic nerve .vacuolation of nerve fibers H\&E $400 \mathrm{X}$.

\section{Result and discussion}

Treated groups(A and B) with malathion showed histopathological changes in peripheral nerves (sciatic nerve) and white mater of spinal cord as shown in figure (1,2,7 and 8) included vacuolation in nerve fibers of both ,these results were in line with that of (13and 14) they found that injection of malathion into the yolk sac of chicken eggs caused reduced growth and weakening of a leg bone, nerve damage two to six weeks after hatching.. This can include suppress the immune system and the body's ability to fight infections, gradual damage to the nervous system during pregnancy, the ability to cause accelerated aging to organs such as the liver and kidneys.preiportal hepatic fibrosis and aggregation of lymphocytes were the main histopathological alterations have been noticed in the present study (fig, 5 and 6). These observations were in line with that of (15), who reported that Repeated exposures to malathion produce toxic effects in the liver regardless of an animal's nutritional status,but malnourished rats, especially those on low protein diets, are more susceptible to the negative effects of malathion.on the other hand, these results were contradicted with that of 16 
malathion was fed to day-old chicks for 2 weeks . The chicks behaved normally and showed a similar growth rate and food consumption to the controls. , and signs of intoxication was observed. At necropsy, no pathological lesions were found. These differences may be attributed to the used organophosphorous type, its dose, route and duration of exposure, species involved, toxicokinetic aspects of insecticide, tissues examined and sampling time17 ). Oral administration of malathion in pigeons produced histopathological lesions of toxicity in kidneys including vacuolation and dilated cortical tubules as shown in fig(3 and 4) .These results were in line with (18) who found the other effects that have been observed in laboratory animals (rabbit and rat)that have been exposed subchronically by inhalation or chronically to diets containing malathion included irritation of the nasal cavity and lungs, decreases in body weight gain, and

\section{References}

1.Abou- Donia, M. B.; Makkawy, H. and Graham, D.J. (1982). Coumaphos: delayed neurotoxic effect following dermal administration in hens $\mathrm{J}$. Toxicol . Environ. Health. 10 : 87 - 99.

2.Abou-Donia, M.B.; Wilmarth, K.R.; Abdel- Rahman, A.A; Jensen, K.F.; Oehme, F.W. and Kurt, T.L. (1996). Increased neurotoxicity following concurrent exposure to pyridostigmine bromide, DEET and Chirpyrifos. Foundam. App. Toxicol. 34:201-222.

3.Al-Zubaidy, M.H. and Mohammad, F.K. (2007). Metoclopramide protection of diazinon - induced toxication in chickens. J.Vet. Sci. 8 (3): 249-254.

4.Bajgar, J. (2004). Organophosphate / nerve agent Poisoning: Mechanism of action, diagnosis, Prophylaxis and treatment. Adv.Cli. Chem. 38:151-216.

5.20-Brown, C.; Gross, W.B. and Ehrich, M. (1986). Effect of Social stress on the toxicity of malathion in possible effects on liver, and kidneys. The histopathological changes of kidney were in line with that of (19) who noticed Proximal tubular vacuolation in the kidneys .Histopathological changes of kidney, were included degenerate cortical tubules associated with loss and disorganization of epithelial lining, also occasional cortical areas of inflammatory cells and or congestion, which shown in figures(3 and 4) were disagreement with (20) who exhibited The treated hens with malathion came into production later and laid slightly. At necropsy no gross or microscopically lesions were found. The result of the study showed dermal fibrosis and dermal inflammatory cells of the skin .Because there is no study exhibited sub chronic toxicity of malathion as organophosphorus insecticide in pigeons, and there is no information related to this work, the present study was accomplished . young chickens. Avian Das. 30: 679-682.

6.Flucke, W, and Kaliner, E. (1987). An examination of acut- neuro toxicity after oral dosing in the hen. Report No. 15430 from Bayer AG, Instatute of Toxicology. Submitted to WHO by Bayer.

7.Gada, A.M; Faris, O.S.; Al- Dewachi, M.O.; Said, M. and Mohammad, F.K. (1999). Determination of Plasma cholinesterase activity cockerels by an electrometric method. Iraq. J. Vet. Sci. 12(2): 255-260.

8.Tomlin, C. D. S., The Pesticide Manual, A World Compendium. 14th ed.; British Crop Protection Council: Alton, Hampshire, UK, 2006; pp 642-643

9.Roberts, T. R. Metabolic Pathways of Agrochemicals - Part 2: Insecticides and Fungicides; The Royal Society of Chemistry: Cambridge, UK, 1998; pp 360367 
10. Reigart, J. R.; Roberts, J. R. Organophosphate Insecticides. Recognition and Management of Pesticide Poisonings, $5^{\text {th }}$ ed.; U.S Environmental Protection Agency, Office of Prevention, Pesticides and Toxic Substances, Office of Pesticide Programs, U.S. Government Printing Office: Washington, DC, 1999; pp 34-47.

11. Costa, L. G. Toxic effects of pesticides. Casarett and Doull's Toxicology: The Basic Science of Poisons, 7th ed.; Klaassen, C. D., Ed.; McGraw Hill Medical: New York, 2008; pp 883-930.

12. Luna, L..G.(1968).Munal of histologcal staining method of the armed institute of pathology $.3^{\text {rd }}$ edition .MC Graw .Hill book .co.London

13. U.S. EPA. Office of Pesticides and Toxic Substances. 1988. Guidance for the reregistration of pesticide products containing malathion as the active ingredient. Washington, D.C.

14. U. S. EPA. Office of Pesticides and Toxic Substances. 1992. Pesticide industry sales and usage: 1990 and 1991 market estimates. Washington, D.C.

15. Schomburg, C.J., D.E. Glotfelty and J.N. Seibur. 1991. Pesticide occurrence and distribution in fog collected near Monterey, California. Environ. Sci. Tech. 25(1): 155-16

16. American Cyanamid Company, New York (1955) Unpublished report

17. Menzer, R. E. "Selection of Animal Models for Data Interpretation," in Toxic Substances and Human Risk: Principles of Data Interpretation. Robert, G. T. and Rodricks, J. V., Eds. Plenum Press, New York, NY, 1987.5-80

18. Malathion Chemical Technical Summary for Public Health and Public Safety Professionals Agency for Toxic Substances and Disease Registry Atlanta, Georgia November 17, 2000

19. Slauter, R.W. (1994) 18-Month oral (dietary) oncogenicity study in mice, test substance malathion. Unpublished report (study No. 668-001) from International Research and Development Corp, Mattawan, Michigan, USA. Submitted to WHO by Cheminova, Lemvig, Denmark.

20. FAO Agricultural Studies, in press; Wld Hlth Org. tech. Rep. Ser.,(1967)
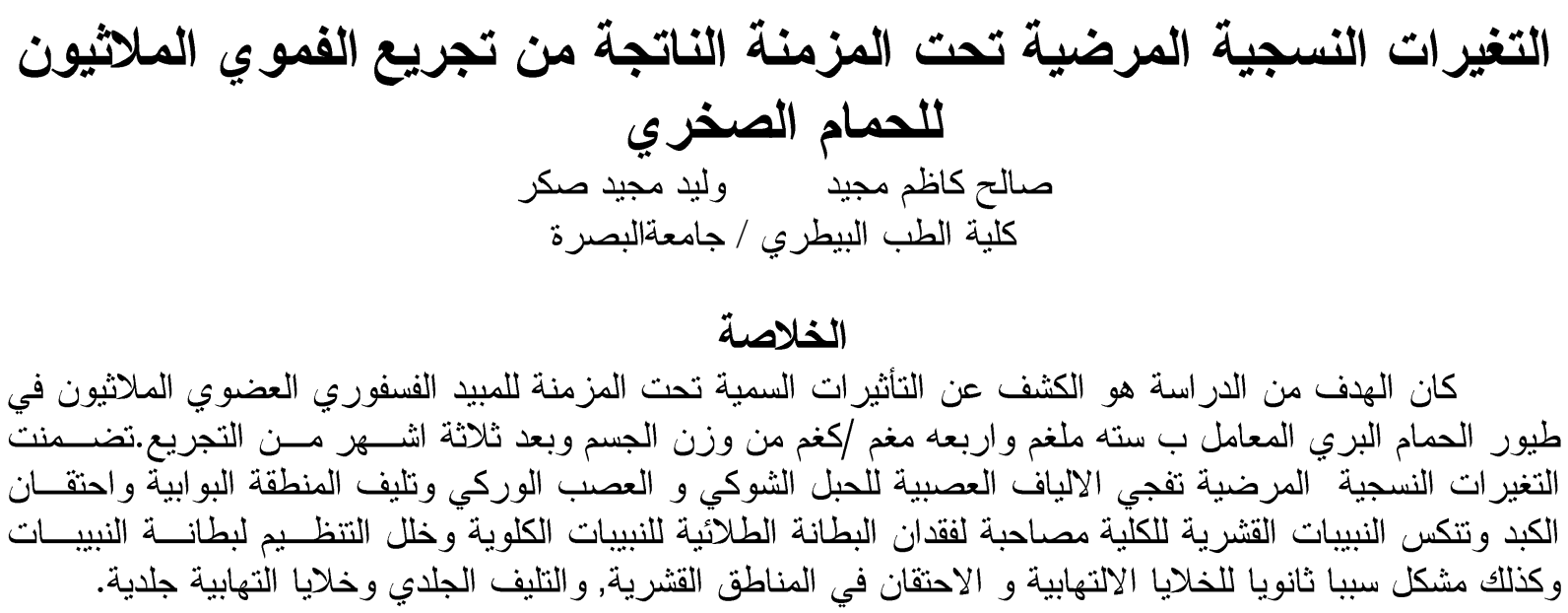